\title{
COVID-19 in Asia - Changing Life as We Know It and the New Normal
}

\author{
Jana S. RO $\check{S} K E R$
}

The present issue of Asian Studies is devoted to the investigation of the causes, effects, and ethical and ideological implications of the COVID-19 pandemic in Asia, particularly in East and South-East Asia. COVID-19 has had a dramatic impact on global societies. There have been enormous changes in the economy, lifestyles, education, culture, and many other aspects of social life (Caron 2021,1). The COVID-19 pandemic has transformed societies, cultures, organizations, infrastructures, and many social services into a completely new reality.

In this respect, the COVID-19 pandemic is without doubt a crisis of global proportions. Therefore, the whole of humanity should try to find a strategic solution to it, and to this end, the importance of intercultural dialog is manifested in a particularly clear and unambiguous way. Indeed, we are convinced that the agenda of intercultural dialogues must play a significant role in the farming of a new transcultural arrangement that could enable us to create new models of social cooperation and connections not only within specific societies and cultures, but also across national and ethnic boundaries. Of course, intercultural dialogue in this sense has necessarily to surpass the empty connotations of a fashionable slogan, which has much too often been used by the ideological narrations of EU bureaucrats. The present journal has often emphasized such endeavours by highlighting the actual and concrete relevance of such cross-cultural interactions and exchanges between Europe and Asia. In this regard, we can specifically point out the recent special issue on collections and evaluation of artefacts, obtained in various material intercultural exchanges between Slovenia and Eastern Asia, entitled East Asia in Slovenia: Collecting Practices, Categorization and Representation. Many authors included in this issue have explicitly laid exposed the importance of concrete and historically contextualized cross-cultural exchanges (see for instance Vampelj Suhadolnik 2021, 7; Grčar 2021, 49, 81; and Motoh 2021, 121).

It is, therefore, no coincidence that the need for such intercultural dialog has become even more evident during the global COVID-19 pandemic.

The first major outbreak of the coronavirus was in China. On the other hand, it must also be noted that the societies of East and Southeast Asia have coped with the pandemic more effectively than most countries in Europe and America 
(Rošker 2021, 41). Consequently, these facts gave rise to several important research questions that were examined from different perspectives within the framework of Asian studies.

Fourteen authors have contributed their research results to this issue. Their papers have been divided into four categories or chapters. The first one includes papers that are proceeding from different theoretical approaches in social theory. The special issue begins with Luka Culiberg's article entitled "Praying for the Cure': Transformations of Japanese Medical Traditions and the Question of Modernity". Through the lens of the current pandemic, it investigates the relation between allegedly oppositional notions of magic and science, which symbolically conveys the meaning and highlights the significance of the questions related to the relation of "tradition" and "modernity". Through a comparative analysis of the focal streams of thought delineating the field of pre-modern and modern Japanese medicine, the author aims to question the Western ideology of "modernity" as an exclusively Western accomplishment. This paper is followed by Tinka Delakorda Kawashima's paper entitled "The Relationless Japanese Society and the Practices of Belonging during the COVID-19 Pandemic", in which the author explores some important changes or modifications of the social structure of contemporary Japanese society, which have certain vital consequences for the political measurements and general situations brought about through the COVID-19 pandemic. In a similar context of specifically Japanese social structures and corresponding cultural mindset and psychological formations, Kyoko Ito-Morales elaborates upon the following questions: "Individual Rights vs. Common Good? A Case Study on the Japanese Self-restraint (jishuku) and COVID-19". The last article in this category is written by Bart Dessein and entitled "Coping with COVID and the Myth of a Collective China". In this paper, the author analyses the development of "hyper-individualism" in the neoliberal context of contemporary China, and exposes several narratives of collectivism as ideologies established and developed on the fringes of cultural myths. In this context, and against the image of wider political and social implications of such ideologies, Bart Dessein emphasizes the importance of what he sees as a revived or new "political agora", especially in times of national and global crises.

The next scope of contents deals with psychological and artistic expressions of fears and anxiety in such critical times. It opens with Federico Picerni's paper “Poets, What Can We Do?': Pandemic Poetry in China's Mobilisation Against COVID-19", in which the author analyses Chinese poems that were written shortly after the outbreak of the pandemic. The analysis proceeds on two parallel levels, a literary and a social one; in this double-dimensional context, it highlights the role of traditional social or public responsibility. In her paper entitled 
"Anxiety, 'Concerned Consciousness' and Their Manifestation in the COVID-19 Pandemic in China", Téa Sernelj investigates the connections between the traditional Chinese "concerned consciousness" and the modern anxiety, which prevailed during the pandemic. Klara Hrvatin's paper, which is the last one in this chapter, explores the "Japanese Artists' Responses to COVID-19: A Mass Revival of the yokai Amabie". The author shows, how the artistic mass revival of the icon called Amabie, which was traditionally used to prevent infection-and, thus, as a cure for individual fear and anxiety - is associated primarily with the period when Japan ordered the closure of the schools as well as the postponement of the 2020 Olympics due to the explosive pandemic situation. In their article "Creative Revitalisation in Rural Japan: Lessons from Ishinomaki", Yao Nancy Ji and Heide Imai also deal with the same symbol and critically introduce its role and function in the context of recovery, regeneration, and local resistance that are partly spreading from Japanese tradition, but can be applied in times of epidemics.

The following three articles belong to empirical studies. Hence, the next chapter is entitled Empirical Studies: Language, Politics, Social and Medical Recovery. In this context, Mateja Petrovčič offers a very good linguistic corpus-based analysis of texts published by the Chinese National Health Commission (NHC). Since this commission is the main authority for health-related issues in the PR China, it is interesting to see how it presents news about the COVID-19 pandemic to English-speaking readers. The analysis clearly shows how Chinese authorities aim to relieve the fears and at the same time block the growth of social negativism and anxiety. This paper is followed by Byoung Yoong Kang's article on "COVID-19 in North Korea and Its Effect on the Cooperation of North and South Korea in the Field of Healthcare". In the light of the fact that there is very little information on these issues in the Western academia (and also in the Western media), this paper presents some especially valuable information on the problems related to political, social and cultural relations between North and South Korea. In light of the pandemic, the author focuses upon certain topical (and thought-provoking) interactions in the fields of medicine, healthcare and science, which were partly altered during the COVID-19 crisis. This scope of empirical studies closes with the paper "Heroes in Harm's Way: COVID-19 Narratives of China as a Form of Soft Power", which was written by Jana Fedtke and her co-authors. This article represents an empirical study, but it also applies an interdisciplinary approach, with a focus on contemporary Chinese history, culture, and politics as well as communication issues and narratives. It examines two Chinese TV shows, and illuminates on the basis of analysing their contents, ideological backgrounds and structures, that they provide positive narratives of the social response to COVID-19 in the sense that they highlight civil courage 
and sacrifice to inspire the Chinese population and contribute in this way to national unification and the development of patriotism.

The last category includes papers connected to different aspects of Asian Ethics and Ontology, relevant in times of crises. The chapter opens with Seongmin Hong's paper "The Pandemic, Ecological Justice, and Zhu Xi's Philosophy". The author highlights the significance of human responsibilities and duties for the safety and well-being of communities in the times of crises through the lens of Naess's concept of "deep ecology", as reflected in Zhu Xi's philosophy. In this context, Hong aims to explain ecological justice by applying Zhu Xi's social equality theory to ecology. This paper is followed by Jana S. Rošker's article, entitled "COVID-19, Digital Tracking Control and Chinese Cosmotechnology". It investigates the specific features of traditional East Asian perceptions of technology as such, as well as their ideational underpinnings, which certainly influence specific Sinic perceptions of digital objects. The author hopes that such an approach can offer us a better understanding of the cultural conditionality of differences and commonalities in the global processes of digitalization and their ontological underpinnings. This scope of contents-and the special issue as such-closes with the paper entitled "The Ethical Foundations of Buddhist Cognitive Models: Presentations of Greed and Fear in the Theravadda Abhidhamma", written by Tamara Ditrich. Through a meticulous analysis of the Indian Buddhist text Abhidhamma, Ditrich detects those elements and factors of human cognition, which allow for an ethical (kusala) position and subsequently, for ethical behaviours. The paper proposes that introducing the cognitive models of ancient India can help us to find new approaches to contemporary ethical challenges, and thus contribute to an alternative understanding of, and responses to, greed and fear, which tend to manifest extensively in times of epidemics.

This comprehensive volume of wide-ranging and interdisciplinary contributions on COVID-19 indicates the great importance and topicality of the subject. Importantly, however, the contributions gathered in this special issue not only provide some concrete answers to the many questions that have arisen in the period of this global pandemic, but have also raised and opened up many important questions that can help us find our way into our common global future.

\section{References}

Caron, Jean François. 2021. A Sketch of the World after the COVID-19 Crisis: Essays on Political Authority, the Future of Globalization, and the Rise of China. Singapore: Palgrave Macmillan. 
Grčar, Mina. 2021. "Ivan Skušek Jr. and His Collection of Chinese Coins.” Asian Studies 9 (3): 47-83. https://doi.org/10.4312/as.2021.9.3.47-83.

Motoh, Helena. 2021. "Lived-in Museum: The Early 20th Century Skušek Collection." Asian Studies 9 (3):119-40.https://doi.org/10.4312/as.2021.9.3.119-140.

Rošker, Jana S. 2021. Kriza kot nevarnost in upanje: etika pandemij, razcvet avtokracij in sanje o avtonomiji v transkulturni perspektivi. Ljubljana: Znanstvena založba FF.

Vampelj Suhadolnik, Nataša. 2021. "East Asia in Slovenia: Collecting Practices, Categorization and Representation." Asian Studies 9 (3): 7-18. https://doi. org/10.4312/as.2021.9.3.7-18. 